\title{
AGEING POPULATION IN NEPAL: CHALLENGES AND MANAGEMENT
}

\author{
Raj Kumar Yadav \\ Department of Population Studies, TU, TRM Campus, Birgunj
}

\begin{abstract}
Ageing is not yet understood as a demographic as well as socio-economic problem in Nepal with adequate reflection in the policy and plan documents. However, gradual decline in fertility, rapidly increasing technological diffusion along with considerable control in mortality increasing ageing have challenged it's properly management. Internal conflicts, poor socio-economic and inadequate resource base of the country have difficulties in coping with the problems of aging espoused with unemployment among adults. Transitions in social status, economic motive and family attitude, norms and values and transformation from joint to nuclear family structure have also challenged its properly rearing and caring. Coherent and aggressive policy and programmed measures are required to combat the issues of elderly as well as welfare for all in Nepal.
\end{abstract}

\section{Keywords}

Ageing, physical disability, mental disorder, loss of memory, less socialization, loss of immunity power.

\section{Introduction}

Ageing is a continuous, universal, progressive, intrinsic, and deleterious process. It is distinct from the physical and mental retardation caused by any other reasons like diseases, disability or any superficial causes. Physical disabilities, mental disorder, characterized by loss of memory and less socialization are some of the formal characteristics of ageing. These characteristics should not be accompanied by causes other than the age. Loss of immunity power develops several physical disabilities in the old age. Ageing in fact is a continuous and universal process which is progressive in nature. Ageing has several dimensions. It is continuous, universal, progressive, intrinsic and deleterious process with the increase in age, loss of immunity power expands and so the attack of diseases increases. Some of the diseases remain dormant for long and come 
into attack once the immunity power of body becomes weak. The rapid increase in world ageing, especially in developing countries, has deemed to develop several questions to planner and government (Hodgson, 1983). The number of older persons has tripled over the last 50 years; it will be more than triple again over the next 50 years.

In 1950, there were 205 million persons aged 60 or over throughout the world. At that time, only 3 countries had more than 10 million people 6o or older: China (42 million), India (2oMillion), and the United States of America (20 million). Fifty years later, the number of persons aged 6o or over increased about three times to 606 million. In 2000, the number of countries with more than 10 million people aged 60 or over increased to 12, including 5 with more than 20 million older people: China (129 million), India (77million), the United States of America (46 million), Japan (30 million) and the Russian Federation (27 million). Over the first half of the current century, the global population 6o or over is projected to expand by more the three times to reach nearly 2 billion in 2050. By 2050, 33 countries are expected to have more than 10 million people 6 o or over, including 5 countries with more than 50 million older people: China ( 437 million), India (324 million), the United States of America (107 million), Indonesia (70 million) and Brazil (58 million) (Hodgson, 1983).

In the period 1950-1955, the global average annual rate of increase in number of persons aged 60 years of over was only slightly higher than the rate for the total population (both around 1.8 per cent). Currently, the growth rate of the older population (1.9 per cent) is significantly higher than that of the total population (1.2 per cent). In the near future, the difference between the two rates is expected to become even larger as the baby boom generation starts reaching older ages in several parts of the world. By 2025-2030, projections indicate that the population over 60 will be growing 3.5 times as rapidly as the total population (2.8 per cent compared to o.8 per cent). Even though the growth rate of the 60 or over age group is expected to decline to 1.6 percent in $2045-250$, it still will be more than 3 times the growth rate of the total population ( 0.5 Percent) by the end of the second quarter of this century ( Hodgson, 1983).

Over the past half- century, both the worldwide drop in fertility and concurrent rise in life expectancy have led to the gradual ageing of the world's population. Since 1950, the share of persons ages 65 and older has risen from 5 percent to 7 percent worldwide. As the map shows, Europe and Japan have led the way, with North America, Australia and New Zealand close behind. However, older persons are now more than 5 percent of the inhabitants in many developing countries and by 2050 are expected to be 19 percent of Latin America's population and 18 percent of Asia's (PRB, 2007).

\section{Present scenario of ageing population}

Among SAARC countries, India has the highest ageing population i.e. 62.1 million followed by Bangladesh i.e. 7.54 million which is presented in Table 1.

Table 1: Ageing population situation of SAARC Countries, 2005-2011 (million)

\begin{tabular}{|l|l|l|l|}
\hline $\begin{array}{c}\text { SAARC Coun- } \\
\text { tries }\end{array}$ & $\mathbf{2 0 0 5}$ & $\mathbf{2 0 0 8}$ & $\mathbf{2 0 1 1}$ \\
\hline India & 44.14 & 57.47 & 62.1 \\
\hline Pakistan & 7 & 7.0 & 7.1 \\
\hline Nepal & 1 & 1.1 & 1.22 \\
\hline Sri Lanka & 1.2 & 1.22 & 1.25 \\
\hline Bhutan & 0.04 & 0.1 & 0.04 \\
\hline Bangladesh & 4.33 & 5.9 & 7.54 \\
\hline Afghanistan & 0.6 & 0.7 & 0.65 \\
\hline
\end{tabular}

Source: PRB, World population data sheet, 2005, 2008 and 2011.

In Nepal, the older population accounts for about 7 percent of the total population and 
a majority (over 6 out of 10) of them are in their sixties. This is expected in view of the recent history of ageing in Nepal. However, about one fifth of the older population is aged 75 and over. This pattern holds for both men and women. The extent of ageing varies, albeit modestly, by gender, rural/urban residence and development regions. The proportion of older persons among men is 6.4 percent. Examination of age distribution of older persons also shows a modest dominance of men over women in almost all age groups except for the age group 75 and over (Table 2). Among the senior citizens, females outnumber men. The age pattern by gender observed for the country as a whole also holds for each development region. Data on sex ratio of older population by age group also reveals increasing dominance of men over women with each successively older age group, excepting age group 75 and over, indicating continuation of excess female over male mortality almost throughout the life span. The pattern is reversed in the oldest age groups in which male mortality exceeds that of female. A similar pattern of imbalanced sex ratio, in which dominance of older men over older women increases with each successively older age group, is observed in almost every development region (CBS, 2003).

Table 2: Ageing situation of Nepal, 1952/54 -2011 (in percent)

\begin{tabular}{|c|c|c|}
\hline Census year & male & female \\
\hline $1952 / 54$ & 4.5 & 5.4 \\
\hline 1961 & 4.8 & 5.6 \\
\hline 1971 & $5 \cdot 3$ & 5.9 \\
\hline 1981 & 5.9 & 5.5 \\
\hline 1991 & 5.9 & 5.7 \\
\hline 2001 & 6.4 & 6.3 \\
\hline 2011 & 6.8 & 7.1 \\
\hline
\end{tabular}

Source: CBS, 2003, census poreliminary report, 2011.

The declining young age population with increased old age population indicates several socio-economic and demographic inter plays prevalent in the country (Table 3). The enhanced level of education, migration towards developed areas, better health and increasing age at marriage espoused explanation of decreasing young age population. This scenario could affect the labor force situation of the country and alarm a rethinking regarding the retirement ages.

\section{Perception regarding ageing}

The ageing as a challenge to the welfare of people is not understood in the realm of policy making and programmed implementation. The issue of ageing has become more challenging because the consequences have not been properly realized and understood in recent past (Acharya, 2006).

Issues of ageing and elderly population are closer to each other but they are not exactly the same. Ageing is the shift or alteration of the population in the age structure, which might have multifaceted response in various age groups including elderly. The reducing proportion of population in much younger ages resulting in the slightly increased proportion of population in reproductive age for a short period could also be the effect of ageing that relatively requires address in the need of young and adult couples. However, most of the concerns of ageing globally and nationally in Nepal are focused on the need of elderly population and mainstreaming them into national development progress (Acharya, 2006).

\section{Demographic trends and its impact}

The age structure of the Nepali population has been changing over the years with a shift towards older ages increasing gradually declined fertility and relatively controlled adult mortality. Political awareness and change in traditional behavior have insisted people to migrate from distant hills and mountains to relatively developed areas where amenities are available. This movement of people has 
resulted in change of food habits, health service women. These factors contribute to ultimate increase in life expectancy at birth and alteration of age structure upwards with challenges to be addressed for the care of elderly people in Nepal.

Furthermore, challenges in employment for young adult people have created pressure for them to move away from home, village/ town as well as the country and abroad. Such movement of young adults creates challenges for the caring of aged people and burden to the remaining women and children hindering their personal career development.

The controlled mortality through immunization and other technological advancement, awareness on the consequences of high fertility and resulted low CEB with potential youth migration from rural areas to urban centers in search of opportunities have made ageing a parallel problem in Nepal. The older are getting older on the one hand and younger have the challenges of life on the other leaving no time to take care of elderly, whereas the government and non-government sector had not anticipated the problem in immediate past. Hence they have no preparation for making support to them. This traumatic condition has left many of families with children away from home. Furthermore, the burning conflicts in distant rural areas have ignited an exodus of young adults in search of shelter in urban areas leaving parents and family (women) with children in village. The elderly population has thus faced multifaceted problems with inadequate government policies and programs:

Welfare for the elderly: - The welfare for the elderly people must be the agenda in three levels. First is obviously the government, second the society or the efforts by nongovernment agencies and third and vital is family. There exists a structural paradigm through which a society functions in every population. The magnitude of the role of people/individual may differ from one social setting to another, one ethnic group to another and one economic construction to another. However, the role of elderly, their welfare and their position in family and community level decision making is almost defined and definite in every sub-population. Gifts to elderly in particular (father's day/mother' day) ceremonies symbolize the responsibility of younger generation to take care of elderly.

There is a provision of the government to run elderly homes in Nepal. The strict condition is that the elderly people have no closer relatives to take care of them. Many aged persons ignored by their own descendants have no place in such elderly homes, or they have to furnish fake information to obtain the facility. If both old spouses are on the street, they have difficulty to get admission in the Government shelters, because the provision is that they should not be in the status of currently married.

The Tenth Five-Year Plan, Nepal has mentioned the better management and services to elderly under the policies related to social welfare, but it has not recognized the ageing process as serious policy thread under the population policy section. A lack of understanding of underpinning demographic indicators that affect socioeconomic development is still prevalent in the Nepalese policy sphere. Elderly homes and related documentations are under the scope the 'Ministry of Women, Children and Social Welfare', which has no institutional network up to grass-root level. Also the unit that distributes the old-age allowance of almost two dollars per month is the wing of 'Ministry of Local Development'. Many elderly are even deprived of this facility as they have failed to produce citizenship certificate or other valid Government documents.

A number of social, spiritual and religious non-governmental organizations have also contributed to support to elderly people in Nepal. They offer their services in various ways to this segment of population. Their services 
include supply of food, clothing, footwear, medicines and clinical service. In addition, the spiritual services as telling the stories from the religious scriptures, devotional songs, and recreational tour to some places are also provided to them. The physical level services as bathing, hair care, nail care, and washing clothes are also provided. Most of the NGOs have a kind of casual service programmes to the elderly. There is a lack of perpetual services that is sustainable and effective. The NGO team returns of the service and elderly also return to their real status. Obviously, a majority of aged people are living in families even with some misunderstanding and with gaps in generations from parents to descendants.

There are also legal provisions mentioning the duties of taking care of parents, grand parents by the family, however the transition in society and family system in Nepal have contributed to loneliness of elderly. The increasing trend of living away from the parental home with own nuclear family and gaps in technology, thoughts, norms and systems values have prevented the old couples to live with their sons and daughter-in-laws.

Economic approach to ageing: - There is paucity of information on the economic aspects of elderly people in Nepal.

Shift of age structure from young to old age has some implications in labour force that displays the elderly from measure income earning sector. When they are their physical capability to work, supervise and monitor naturally reduces and the ambitious younger generations replace them. In this process, the elderly lose the decision making authority, command on resource base and become depend even for their ordinary needs to be fulfilled. Younger generations employment opportunities must be increased but not in the cost of deprivation of the older generation.

Nepal has no sound official social security system. Whatever property inherited from the ancestors and the elderly can retain with them as the security measures in changing social phenomena. Increasing international gap and lack of understanding has resulted in hesitation of parents to transfer the property to descendents to ensure their future, which in turn has been creating further conflicts between the generation and causing for deteriorated security of elderly people.

There is lack of separate effective scheme for elderly peoples' health care facilities in Nepal. Whatever facilities are rendered by the Government, non-Government and private agencies are for all and senior citizens have also been there to avail services. Specific clinics of elderly, separate wards or some special arrangements to ease their health hurdles and public expenditure segregated for these activities are in absence. Nevertheless, out of the total health expenses, a large share go to the care of elderly is rather obvious.

The Government and some public enterprises have the scheme of pension in Nepal. Less than two percent of populations are in the government services and, therefore, that does not ensure financially secured future of all population. Moreover, an old-age allowance of US dollar two per month does not satisfy the need of the elderly people. Schemes of self reliance of elderly people for their continuous participation in society can upgrade their living standards and utilized their experience and skills. Instead of focusing on the pensions system to only former government employees an income generating system that pays for the experience and skills of elderly is more appreciated.

\section{Management of ageing in Nepal}

In Nepal, different ages are used as starting of ageing. At the Government level, the retirement for civil servants is fixed at 58 years. Therefore civil servants, the ageing are supposed to start after retirement. In universities, the retirement age of teachers and administrator is 63 years. Therefore their 
ageing starts after 63 years. For legal activities and granting of pension to general mass, the age fixed for a person to be old is 75 years.

The joint family structures with great grand parents are rare in these days. The roles have been changed dramatically that there are no people to listen to the elderly. Madrid convention has focused on the intergenerational cooperation to further strengthen the stature of elderly people in family. The westernized and individualized family model does not support to these ideals. Nepal, being a traditional society had enjoyed the familial ties with elderly people in past, however, the changed family model does not support to elderly and people need their own income sources even to fulfill ordinary demands in old ages.

Among the three traditional, transitional and modern societies, the gap is much widened in transitional societies. Prevalent dualism of traditional and modern behavior encourages controversy between the generations and many times such conflicts ruin the families. The difficulty to accept change among elderly people and lack of understanding of needs of elderly among the young adults are the major barriers of a smooth family life. Government, non-government and private sector's efforts to establish coherence between and among generation are required especially in the transitional societies.

A surveydepicts that thereexists a considerable gap in generations in Nepal (Himal Magazine, April 2005). The younger generation has ambitions of modernization and older generation wants to continue traditional norms and values. The gap is translated into family conflicts and migration of the member of younger generation towards urban centers or abroad. The intergenerational solidarity as perceived by the Madrid Assembly (UN,
2002: 17) must be made a target with adequate advocacy especially in transitional societies (MoHP, 2005).

\section{Conclusion}

There is little literature available on present scenario, trends, impacts, welfare and management of ageing in Nepal. Ageing is only an economic issues but also a social, cultural and political one of the country. Most of the elders are fighting the losing battle of survival. The Government and other concerned agencies should conduct a compressive survey covering all aspects of ageing population: size, age structure, expertise and area of interest to formulate police regarding elderly population. These agencies need to work together to create awareness among communities and to make productive use of elderly population so that the elderly generation can live their rest of life with dignity. At the same time elderly issues should also viewed from gender perspective.

\section{References}

Acharya, B. (2006). Population ageing and its challenge in Nepal. Nepal Population Journal, 13 (12), Page 79-89.

CBS. (2003). Population monograph of Nepal (Vol. II). Kathmandu: Author.

CBS. (2011). Census preliminary report. Kathmandu: Author.

MoHP. (2009). Sandrav Samagri. Janashankhiya Mahasakha, Kathmandu: Author.

PRB. (2007). World Population Data Sheet. Washington. Author.

Singh, M.L. (2003). Ageing of the Population of Nepal, Population Monograph of Nepal (Vol. II). Kathmandu: CBS. 